\title{
Improving Student Learning in an Entry Level Construction Management Course Through the Application of a Social Constructivist Approach to Teaching
}

\author{
Patrick Brittle, Assistant Professor \\ California State University, Chico \\ Chico, California
}

\begin{abstract}
When students initially begin their pursuit of a degree in Construction Management (CMGT), the first CMGT courses they take address a wide breadth of foundational concepts. At the time of taking these entry level courses, most of these new CMGT students have little to no experience in the construction industry. This lack of experience presents a significant challenge for these students to understand the relevancy and real-world application of the concepts they are being taught. Often times these entry level courses utilize a traditional teaching method, where the instructor delivers the concepts to students via lectures. In turn, students focus on memorizing the delivered information, with little understanding of how the information they are taught is used in the construction industry. In this paper the author will demonstrate how a social constructivist approach was used in an entry level CMGT course to design a group project. This group project required students to relate the concepts taught in class to an actual construction project, resulting in improved student understanding of the concepts taught. This study is significant in that similar social constructivist approaches can be used in other entry level CMGT courses to greatly improve the quality of student learning.
\end{abstract}

Key Words: Social Constructivism, Student Learning, Collaborative Learning, Teaching Pedagogy

\section{Introduction}

A unique challenge exists for Construction Management (CMGT) students taking their first required courses within their major. This challenge lies in the fact the students are being introduced to many new concepts often with limited experience, or in most cases no experience, in the construction industry to give context to the new information being taught. Learners receive information, interpret this new information, and then attempt to relate it to pre-existing knowledge and experiences to 
contextualize the information (Krajcik et al., 1999). For a student to gain a meaningful understanding of a concept, they need to be able to make meaningful connections between the new information received and prior knowledge (Ausubel et al., 1968). Given the lack of experience and prior knowledge of the construction industry, these entry level CMGT students often struggle to gain an appropriate level of understanding of the content being taught in their first CMGT courses.

CMGT 100 - Concepts of Construction is the first major course for Construction Management students at California State University (CSU), Chico. This course serves as an introduction and overview of the construction industry, addressing such topics as: project chronology, project delivery systems, contract types, project players and responsibilities, objectives of successful projects, and more. As evidenced, there is a wide variety of concepts introduced to the students throughout this course. The challenge for these students is to absorb this influx of information and understand the context and relevance of this information as it relates to the construction industry.

The author of this paper has been the instructor of this CMGT 100 course for the previous five semesters. The first two semesters which the author taught this course revolved around a more traditional teaching format where the instructor delivered content to the students via class lectures. In turn, students were tasked with receiving and remembering this information. Student comprehension was assessed based on assignments, quizzes and exams. In reviewing student feedback on the course, it became evident to the instructor this teaching method was not conducive to quality student learning. The course content was delivered mainly via lectures and thus students became passive learners.

Additionally, the assessments were structured assignments, quizzes and exams which mainly required students to regurgitate the information the instructor delivered. In an effort to improve student learning and engagement in the course, the instructor revised the structure of the course to include a group project in lieu of the final exam. The instructor designed this group project based on the social constructivist teaching theory. In this paper the author will discuss the implementation of this group project in the CMGT 100 - Concepts of Construction course at CSU, Chico during the Fall 2019 semester as well as the resulting student learning experiences in completing this project.

\section{Literature Review}

A traditional teaching methodology follows that of the "receptional" approach where the teacher transmits information to the students to receive and process (Krajcik et al., 1999). With this approach, students are often operating as passive learners where they observe, receive and process the information being delivered. This lecture-focused approach relies on concepts that are fixed, wellstructured and interconnected by the instructor to deliver to the student. As a result, students learn concepts in a limited framework and have little chance to apply these concepts to varying situations, which is needed outside of the academic setting (Chinowsky et al., 2006). The most common means with which students engage with course material in a traditional teaching methodology is through static means such as readings, homework, and tests (Angelides et al. 2000).

The traditional teaching approach often revolves around students remembering the delivered information, however; knowledge is not obtained by simply memorizing information. Rather, knowledge is constructed by the learner and their experiences (Krajcik et al., 1999). For students to make sense of the information themselves requires an active engagement on the students behalf. Students learn information and can apply it better when they rephrase the information in their own words, discuss the information with others, and explain to others what they've learned (Schmidt et al. 2015). Modern cognitive psychology further supports this idea, suggesting the instructor's role is to 
guide constructive activities but true learning takes place as a result of the learner's actions (Bereiter and Scardamalia, 1992). Given these limitations, the traditional teaching pedagogy is becoming more heavily scrutinized, especially within the college classroom setting, with a case being made that students would learn more effectively if the typical lecture centered approach were abandoned (Scott \& Ghosh, 1992).

The constructivist teaching theory is a stark contrast to that of the receptional approach. Rather than students acting as passive learners, the constructivist teaching theory focuses on having students actively participate in the learning process to construct their own knowledge (Amineh and Asl, 2015). This is especially important when students may not have sufficient pre-existing knowledge, such as in entry level construction management courses. In instances where students are learning material that they often do not have prior experience or reference to draw from, it's especially important that active engagement on behalf of the learner takes place (Entwistle \& Entwistle, 1992).

The constructivist teaching theory is based on the premise that human beings are active learners who construct knowledge based on experiences and through their learning efforts they give meaning to these experiences (Frank et al., 2003). The three most common variations of constructivism consist of radical, contextual and social constructivism (Frank et al., 2003). The social constructivist approach revolves around the central theme that the learner must construct knowledge and understanding through interactions with others (Vygotsky, 1986). According to Krajcik (1999), a social constructivist model for teaching consists of the following five main features:

1. Active Engagement - students engage with the material being taught.

2. Use and Application of Knowledge - students reference prior knowledge and further construct their understanding through referencing other sources.

3. Multiple Representation - students create and are evaluated on a variety of assessments or assignments to gauge their constructed understanding of the concepts.

4. Use of Learning Communities - students form learning communities, such as working in groups, where knowledge is further developed through collaboration.

5. Authentic Tasks - students perform tasks focused on ensuring the content or topic at hand is relevant to the student, thus increasing student motivation to learn the concepts.

\section{Creating a Group Project Based on Social Constructivism}

The implementation of the group project for CMGT 100 was done in the Fall 2019 semester at CSU, Chico. There were a total of 128 students enrolled in the course, which was broken up into two separate class sections; one section of 61 students and another section of 67 students. Within each of the two class sections, students were divided into randomly assigned groups of 3-4 students to work together throughout the semester to complete their group project. The instructor designed the final project, herein referred to as the "final project" or "group project," around the social constructivist theory. The objectives of the instructor in implementing this group project were as follows:

1. Objective \#1 - Improve student understanding of the course concepts.

2. Objective \#2 - Improve the relevancy of the course concepts to the students through relating these concepts to an actual construction project.

3. Objective \#3 - Validate social constructivism as a successful teaching methodology for this CMGT 100 class. 
Table 1 outlines how the group project was designed to account for each of the five main features of the social constructivist model of teaching.

Table 1

Incorporation of social constructivist features into the group project design

\begin{tabular}{lcl}
\hline $\begin{array}{l}\text { Social Constructivist } \\
\text { Feature }\end{array}$ & \multicolumn{2}{l}{ Elements of Group Project to Align with Social Constructivist Features } \\
\hline 1. Active Engagement & - & $\begin{array}{l}\text { Student groups participated in the conference calls with their } \\
\text { assigned Project Manager } \\
\text { Student groups presented their project to the audience }\end{array}$ \\
\hline $\begin{array}{l}\text { 2. Use and Application } \\
\text { of Knowledge }\end{array}$ & - & $\begin{array}{l}\text { Students constructed knowledge in relating the course } \\
\text { concepts to their assigned construction project }\end{array}$ \\
\hline $\begin{array}{l}\text { 3. Multiple } \\
\text { Representations }\end{array}$ & - & $\begin{array}{l}\text { Student groups completed various assignments: Paper Outline, } \\
\text { Rough Draft, Final Draft, and Final Presentation }\end{array}$ \\
\hline $\begin{array}{l}\text { 4. Use of Learning } \\
\text { Communities }\end{array}$ & - & Student worked collectively as a group throughout the project \\
\hline 5. Authentic Tasks & - & $\begin{array}{l}\text { Relevancy of the course material to similar projects the } \\
\text { students will be working on upon entering the industry } \\
\text { Relevancy in interacting with the Project Managers on the } \\
\text { actual construction projects }\end{array}$ \\
\hline
\end{tabular}

This group project was unique in that the instructor had industry Project Managers (PM's) for construction companies participate. The instructor contacted a select group of PM's based in Northern California to identify a construction project that would provide a good opportunity for students to apply the concepts discussed in class. The PM's provided detailed information on their selected construction project such as the method of award, the project players, contract type, and other features of the project related to cost, quality, safety and schedule metrics for the project. Each student group was assigned one of these actual construction projects as the basis for their group project. Another unique feature of this group project is that each student group participated in a conference call with their project's PM. The conference call allowed the student group to interact with their PM and hear about their project first-hand as well as ask any questions they may have on their construction project.

The course material throughout the semester was still delivered via the traditional lecture methodology; however, the group project was used as a means for students to actively engage and relate the course content to an actual construction project. The group project was assigned at the midway point of the semester and was organized such that each group had a deliverable to complete and submit every two weeks up until the end of the semester. The instructor required these sequential deliverables to ensure students progressively worked on their project. The following itemized list outlines the sequential deliverables which each group was required to complete:

1. Paper Outline - organize the content to be included in the Rough Draft research paper.

2. Conference Call with Project PM - participate in a conference call with the PM for the group's assigned project.

3. Rough Draft: - create a Rough Draft research paper based on their Paper Outline and notes from the conference call. 
4. Final Draft - create a Final Draft research paper, which was to account for instructor comments from the graded and returned Rough Draft.

5. Final Oral Presentation - present the specifics of the group's construction project to an audience of CMGT faculty and local industry professionals.

\section{Methodology}

Once complete with the project students were requested to participate in an online survey. Of the 128 students who participated in the group project, 104 students completed the survey, resulting in an $81.3 \%$ response rate. The survey consisted of 15 questions, addressing a variety of areas related to the class. A 5-point Likert scale was utilized for the majority of questions, with two open-ended questions provided students the opportunity to elaborate on their experience. The open-ended questions were categorized to group together similar responses as a means to gather data and analyze trends. For the purposes of this paper, only those questions directly related to the objectives sought to be proved in this paper will be addressed and reviewed as part of the Results section below.

\section{Results}

The survey results were first summarized and the data analyzed as it relates to Objective 1: "Improve student understanding of the course concepts." Two of the survey questions in particular provided insight into whether Objective 1 was achieved:

1. Question 1: What was the biggest benefit of this final project for you as a student of this class? (Open-ended response)

2. Question 2: The final project improved my understanding of the concepts taught in class by reinforcing them through relating them to a construction project (5-Point Likert scale)

The student responses to Question 1 were very telling as it allowed students to summarize their experience of the final project in their own words. The following were excerpts from student responses to this question:

- "A chance to work with other students in the class and work together to understand the concepts"

- "It was more hands on and gave me a better understanding of all the concepts"

- "Combining together all of the elements of the project helped apply the understandings of the class"

- "Looking at an actual construction project is a lot more interesting than just learning the concepts and so this project helped me improve my knowledge of all of the concepts we learned in class."

In order to perform data analysis as it relates to this Question 1, the instructor grouped similar open ended student responses into categories. Figure 1 summarizes the findings of these categorized responses and shows that $28 \%$ of student responses indicated the biggest benefit of the group project was that it improved their understanding of the concepts taught in class (third column from the left). This is significant as these student responses directly support and align with Objective 1. Being that 
these response fields were open-ended, students had the liberty to address any benefit they perceived and yet the majority of students support the instructor's sought out goal of Objective 1 .

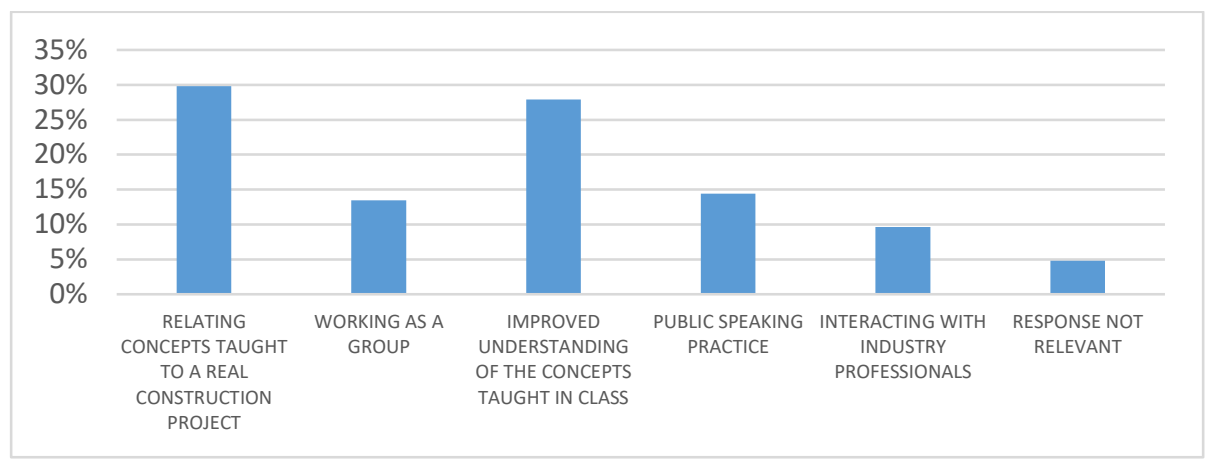

Figure 1: Summary of student responses to Question 1 - "What was the biggest benefit of this final project for you as a student of this class?"

Question 2 utilized a 5-point Likert scale, with response options ranging from "strongly agree" to "strongly disagree." Figure 2 shows the distribution of these responses, with $45.2 \%$ of students strongly agreeing, $51.9 \%$ of students agreeing and $2.9 \%$ of students taking a neutral stance with the statement in Question 2. In combining the "strongly agree" and "agree" response, this culminates in $97.1 \%$ of the class supporting the statement the final project improved their understanding of the concepts taught in class. The survey results from Question \#'s 1 and 2 are significant in supporting findings that Objective 1 was achieved.

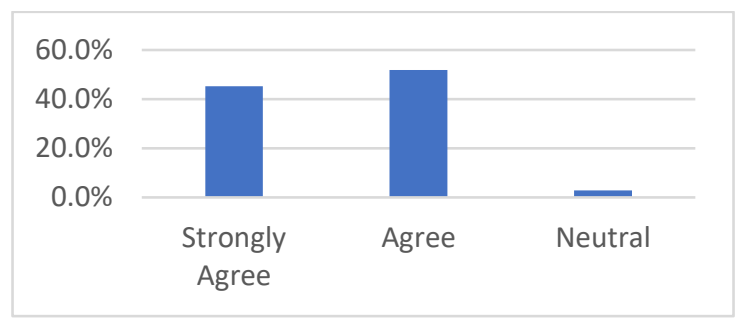

Figure 2: Summary of student responses to Question 2 - "The final project improved my understanding of the concepts taught in class by reinforcing them through relating them to a construction project."

The survey results were next summarized and the data analyzed as it relates to Objective 2: "Improve the relevancy of the course concepts to the students through relating these concepts to an actual construction project." Two of the survey questions in particular provided insight into whether Objective 2 was achieved:

1. Question 1: What was the biggest benefit of this final project for you as a student of this class? (Open-ended response)

2. Question 3: Using an actual construction project as the basis for the Final Project made the content from the class more tangible and relatable. (5-point Likert scale) 
The same categorization of student responses from Figure 1 can be used to gauge student responses related to Objective 2. As indicated in Figure 1, approximately $30 \%$ of open-ended student responses addressed the benefits of relating the concepts taught in class to a real construction project (first column on the left). Additionally, the following are valuable excerpts from student open-ended responses which specifically address Objective 2:

- "The overall biggest benefit of this project was being able to apply the concepts learned and see a real life project. The project was a good source of applying information and making it more memorable."

- "The biggest benefit of this project is being able to actually see and understand how all of the topics taught in class are related in the real construction industry."

- "What we learned in class was all conceptual in a way, and then when I saw real life project with real budgets, and information, it made it feel real."

- "It made the class more relatable to the real construction world."

Question 3 also utilized a 5-point Likert scale. Figure 3 summarizes the student responses to this question, which $49.0 \%$ of students "strongly agree," $43.3 \%$ of students "agree" and another $7.7 \%$ of students were "neutral" with the statement posed in Question 3. In combining the "strongly agree" and "agree" response, this culminates in $92.3 \%$ of the class supporting the statement that using an actual construction project made the content from the class more tangible and relatable. The survey results from Question \#'s 1 and 3 are significant in supporting findings that Objective 2 was achieved.

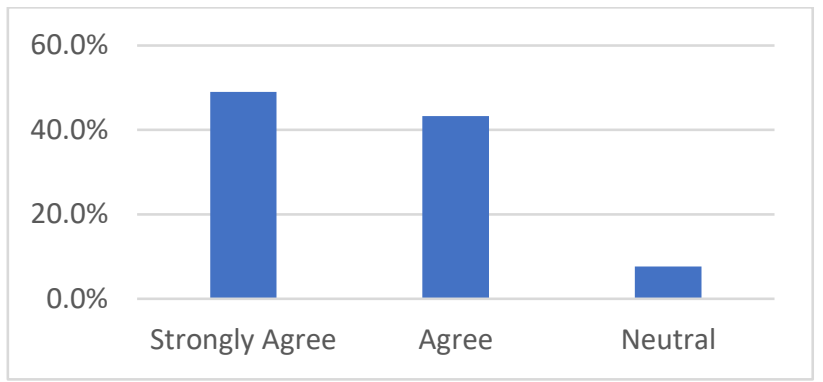

Figure 3: Summary of student responses to Question 3 - "Using an actual construction project as the basis for the Final Project made the content from the class more tangible and relatable."

The survey results were also summarized and the data analyzed as it relates to Objective 3: "Validate social constructivism as a successful teaching methodology for this CMGT 100 class." Two of the survey questions in particular provided insight into whether Objective 3 was achieved:

1. Question 1: What was the biggest benefit of this final project for you as a student of this class? (Open-ended response)

2. Question 4: This Final Project improved my overall learning experience of this class. (5point Likert scale)

The same categorization of student responses from Figure 1 can be used to gauge student responses related to Objective 3. The remaining categories of students responses outlined in Figure 1 show that $13 \%$ of students enjoyed working in groups (second column from the left), $14 \%$ of students positively reflected on the oral presentation component (fourth column from the left), and another $10 \%$ enjoyed working with the industry PM's (fifth column from the left). These response categories highlight the 
other benefits of the group project as perceived by the students. The following are excerpts from student open-ended responses which specifically address Objective 3:

- "We got to work with real companies and real projects to put all the info we learned in class into the real world. It's a nice transition from classroom to work site."

- "Better learning the steps of a project and what contributes to the completion. The conference call was super cool."

- "It was very cool to talk to a project engineer and receive advice from someone in the industry"

In analyzing the responses for Question 4, which are summarized in Figure 4, 48.1\% of students strongly agreed, $44.2 \%$ of students agreed, $6.7 \%$ of students were neutral and $1.0 \%$ of students disagreed with this statement. In combining the "strongly agree" and "agree" responses, this resulted in a total $92.3 \%$ of students who felt the project improved their learning experience in the class. The survey results from Question \#'s 1 and 4 are significant in validating Objective 3.

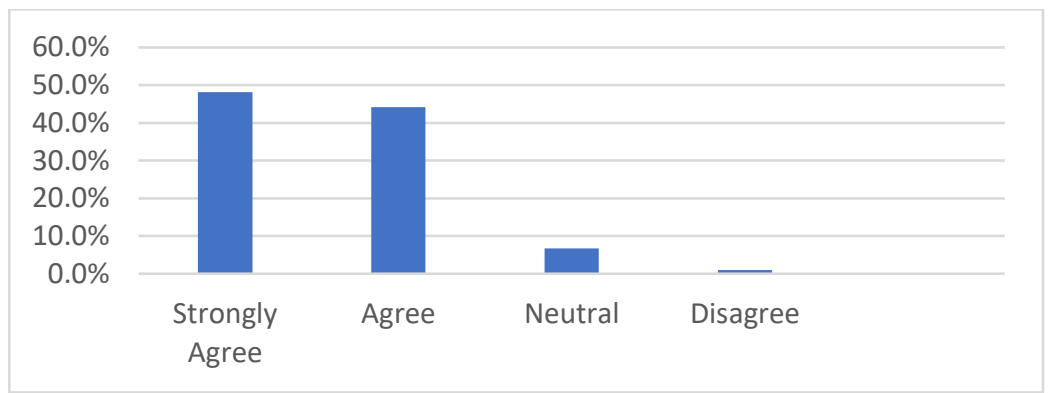

Figure 4: Summary of student responses to Question 4 - "The Final Project improved my overall learning experience of this class."

\section{Summary and Conclusion}

Introductory construction management courses pose unique challenges for CMGT students to effectively learn the course content because they often have little to no prior industry experience. With limited pre-existing knowledge, it becomes increasingly challenging for these new CMGT students to give context and adequately understand the new information they are receiving. A social constructivist approach to teaching offers a means to enhance student learning given these constraints. This social constructivist approach requires five features to be accounted for: active engagement, use and application of knowledge, multiple representations, use of learning communities, and authentic tasks. The group project incorporated into CSU, Chico's CMGT 100 course was designed around incorporating these five features. Rather than acting as passive learners, students were able to actively contribute in forming their understanding of the course material by relating the material discussed in class to an actual construction project. The survey results from the students supported the intent of the group project in achieving the three sought after Objectives: 1) students achieving a better understanding of the course concepts 2 ) improve the relevancy of the course concepts to the students through relating the concepts to an actual construction project and 3) validate social constructivism as a successful teaching methodology for this CMGT course. Based upon this papers positive research results, faculty teaching other entry level CMGT courses may be encouraged to apply the social constructivist approach to enhance the learning experience for their students as well. 
The limitations of this research consist of the fact the student survey was based on qualitative inputs from students. The students based their responses on their perceived improvements in learning and understanding of the course content. While they perceived that the group project improved their learning, this is their perception and may not be valid. Future research regarding this topic should utilize quantitative data, requiring students to demonstrate their understanding. This would provide a more direct and objective means of assessing student learning as a result of the group project.

This research offers promising results to support the implementation of social constructivism in other entry level CMGT courses to enhance student learning. Not only can similar types of group projects be implemented in these entry level courses but also incorporating construction industry professionals would be beneficial. Many CMGT programs at Universities have close ties to construction industry professionals and through collaboration with students, this can further enhance student learning.

\section{References}

Aminah, R., and Asl, H., (2015). Review of constructivism and social constructivism. Journal of Social Sciences, Literature and Languages, 1(1), 9-16.

Angelides, D. C., Poulopoulos, A., Avgeris, I., and Haralampous, P. (2000). Case studies and information technology in civil engineering learning. J. Prof. Issues Eng. Educ. Pract., 126(3), pp. 125-132.

Ausubel, D.P., J.D. Novak, and Hanesian, H.. (1968). Educational psychology: A cognitive view. $2^{\text {nd }}$ ed. New York: Holt, Rinehart and Winston

Bereiter, C., and Scardamalia, M. (1992). Cognition and Curriculum. In P.W. Jackson (ed.), Handbook of research on curriculum. Macmillan Pub. Co.

Chinowsky, P., Brown, H., Szajnman, A., and Realph, A. (2006). Developing knowledge landscapes through project-based learning. ASCE Journal of Professional Issues in Engineering Education and Practice, 132(2), pp. 118-124.

Entwistle, A., and Entwistle, N. (1992). Experiences of understanding in revising for degree examinations. Learning and Instruction, Vol.2, pp.1-22.

Frank, M., Lavy, I., and Elata, D. (2003).Implementing the project-based learning approach in academic engineering course. International Journal of Technology and Design Education, 13,273288.

Krajcik, J., Czerniak, C., and Berger, C. (1999). Teaching children science: A project-based approach. McGraw-Hill Companies, Inc.

Schmidt, H., Wagener, S., Smeets, G., Keemink, L., and Molen, H., (2015). On the use and misuse of lectures in higher education. Health Professions Education, 1(1), 12-18.

Scott, L., and Ghosh, S., (2016). Collaborative Approach in Construction Education: Towards a More Constructivist Experience. 52 ${ }^{\text {nd }}$ ASC Annual International Conference Proceedings.

Vygotsky, L., (1986). Thought and language. Translated by A. Kozulin, MIT Press, Cambridge, Mass. 